\title{
Dissection of appetitive conditioning : does impulsivity play a role?
}

Citation for published version (APA):

Papachristou, H., Nederkoorn, C., Beunen, S., \& Jansen, A. (2013). Dissection of appetitive conditioning : does impulsivity play a role? Appetite, 69, 46-53. https://doi.org/10.1016/j.appet.2013.05.011

Document status and date:

Published: 01/10/2013

DOI:

10.1016/j.appet.2013.05.011

Document Version:

Publisher's PDF, also known as Version of record

Document license:

Taverne

Please check the document version of this publication:

- A submitted manuscript is the version of the article upon submission and before peer-review. There can be important differences between the submitted version and the official published version of record.

People interested in the research are advised to contact the author for the final version of the publication, or visit the DOI to the publisher's website.

- The final author version and the galley proof are versions of the publication after peer review.

- The final published version features the final layout of the paper including the volume, issue and page numbers.

Link to publication

\footnotetext{
General rights rights.

- You may freely distribute the URL identifying the publication in the public portal. please follow below link for the End User Agreement:

www.umlib.nl/taverne-license

Take down policy

If you believe that this document breaches copyright please contact us at:

repository@maastrichtuniversity.nl

providing details and we will investigate your claim.
}

Copyright and moral rights for the publications made accessible in the public portal are retained by the authors and/or other copyright owners and it is a condition of accessing publications that users recognise and abide by the legal requirements associated with these

- Users may download and print one copy of any publication from the public portal for the purpose of private study or research.

- You may not further distribute the material or use it for any profit-making activity or commercial gain

If the publication is distributed under the terms of Article $25 \mathrm{fa}$ of the Dutch Copyright Act, indicated by the "Taverne" license above, 
Research report

\title{
Dissection of appetitive conditioning. Does impulsivity play a role?
}

\author{
Harilaos Papachristou ${ }^{\mathrm{a}, \mathrm{b}, *}$, Chantal Nederkoorn ${ }^{\mathrm{a}}$, Shalana Beunen ${ }^{\mathrm{a}}$, Anita Jansen ${ }^{\mathrm{a}}$ \\ ${ }^{a}$ Maastricht University, Faculty of Psychology and Neuroscience, P.O. Box 616, 6200 MD Maastricht, The Netherlands \\ ${ }^{\mathrm{b}} \mathrm{U}$-Center, Epen, The Netherlands
}

\section{A R T I C L E I N F O}

\section{Article history:}

Received 29 January 2013

Received in revised form 9 April 2013

Accepted 1 May 2013

Available online 23 May 2013

\section{Keywords:}

Pavlovian appetitive learning

Cue reactivity

Craving

Expectancy

Liking

Impulsivity

\begin{abstract}
A B S T R A C T
Rationale: It is generally assumed that cue-reactivity results from appetitive pavlovian learning. This is the reason for applying cue exposure with response prevention interventions in the treatment of substance and eating disorders. However, not all appetitive conditioned responses are equally sensitive to extinction. Additionally, impulsivity traits appear to moderate cue-reactivity. Nevertheless, there has been little research on the role of impulsivity traits in the learning of different appetitive response systems.

Objectives: The purpose of the present study was (i) to replicate Van Gucht et al.'s (2010) findings, in particular, the acquisition and the differential extinction of appetitive learned responses and ii) to investigate the role of impulsivity traits in appetitive learning.

Methods: Participants $(n=50)$ took part in a single laboratory session. Impulsivity traits (reward sensitivity, response inhibition, sensation seeking) were measured at the beginning of the session. A paradigm similar to Van Gucht et al.'s (2010) was used for the acquisition and extinction of subjective conditioned responses for milk chocolate (craving, expectancy, and liking).

Results: The acquisition of appetitive responses was successful. Unlike craving and liking, the extinction of expectancy was fully successful. Impulsivity traits played no role in the acquisition and extinction of appetitive conditioning.

Conclusions: The results support the differential sensitivity of different appetitive response systems to extinction. The lack of findings for the role of impulsivity traits in appetitive learning shows that the question of how impulsivity affects appetitive behaviour still remains open. Theoretical and methodological issues and clinical implications of the findings are discussed.
\end{abstract}

(c) 2013 Elsevier Ltd. All rights reserved.

\section{Introduction}

Cue reactivity is a well-researched phenomenon in substance abuse and eating disorders (Drummond, 2001; Jansen, 1998). When addicts, binge eaters or overweight participants are faced with drug-related cues, they often exhibit changes in physiology and increases in self-reported craving (Carter \& Tiffany, 1999; Ferriday \& Brunstrom, 2011; Jansen, 1998). It has been argued that learning mechanisms are involved in cue reactivity. According to this view, arbitrary cues repeatedly paired with the reinforcing and rewarding effects of drugs/food become conditioned stimuli $(\mathrm{CS}+)$ and elicit conditioned responses (CR: e.g., craving) as a result of pavlovian learning (Drummond, 2001; Jansen, 1998). Most important, there is empirical evidence that cue reactivity motivates drug- and food-seeking behaviour, precipitates relapse in abstinent substance users, and may be involved in the maintenance of an overweight body (Birch, McPhee, Sulivan, \&

* Corresponding author at: Maastricht University, Faculty of Psychology and Neuroscience, P.O. Box 616, 6200 MD Maastricht, The Netherlands.

E-mail address: h.papachristou@maastrichtuniversity.nl (H. Papachristou).
Johnson, 1989; Cornell, Rodin, \& Weingarten, 1989; Drummond, 2001; Tetley, Brunstrom, \& Griffiths, 2009).

Assuming that cue reactivity is a learned response, learning procedures such as acquisition and extinction could be applied to it (Bouton, 2007). In classical conditioning, an extinction procedure refers to the presentation of the CS+ in the absence of the unconditioned stimulus (US), which diminishes or abolishes the CR (Bouton, 2007). This is the main principle behind the use of the cue exposure with response prevention interventions in many treatment programs for addiction and eating disorders (Conklin \& Tiffany, 2002; Jansen, 1998; Toro et al., 2003). The goal is to expose the patient to drug/food-related cues and elicit a robust conditioned response (e.g., a strong craving response), while drug/food-taking is prevented. This procedure should extinguish the learned responses (e.g., craving) to these cues (Conklin \& Tiffany, 2002; Jansen, 1998). However, the effectiveness of this intervention in treatment is not always successful (Conklin \& Tiffany, 2002).

Among many reasons for its reduced effectiveness (Conklin \& Tiffany, 2002), one could be that there are considerable individual differences in cue reactivity. Personality factors may explain some of the variability in cue-elicited responses (Papachristou, 
Nederkoorn, Corstjens, \& Jansen, 2012; Papachristou, Nederkoorn, Havermans, van der Horst, \& Jansen, 2012). For example, it has been found that different impulsivity traits moderate cue-elicited craving and physiological cue reactivity in heavy and dependent alcohol drinkers and tobacco smokers (Doran, McChargue, \& Spring, 2008; Doran, Spring, \& McChargue, 2007; Franken, 2002; Kambouropoulos \& Staiger, 2001; Papachristou, Nederkoorn, Havermans, et al., 2012; Papachristou et al., 2013). In general, impulsive participants react more to cues. These findings might explain partly why highly impulsive people are found to be more prone to addiction and overconsumption of food (Dawe \& Loxton, 2004; Verdejo-Garcia, Lawrence, \& Clark, 2008). In addition, these findings imply that cue exposure with response prevention may be more beneficial for impulsive individuals who may run a higher risk of relapse due to their stronger cue reactivity. Finally, their strong cue-elicited responses may have more difficulty to extinguish compared to the weaker cue-elicited responses of individuals low in impulsivity. Thus, extinction might prove more difficult but also more beneficial for people high in impulsivity.

Another issue is that not all conditioned responses show the same sensitivity to extinction. Evidence suggests that expectations of the reward are more sensitive to extinction compared to more hedonic responses. For example, Van Gucht, Baeyens, Vansteenwegen, Hermans, and Beckers (2010) and Van Gucht, Vansteenwegen, Beckers, and Van den Bergh (2008) have shown that although acquired expectancy for chocolate in response to a CS+ was extinguished successfully, acquired craving and liking responses were not. This differential sensitivity to extinction may indicate that different psychobiological mechanisms underlie these responses and it may also explain some of the failures of the cue exposure with response prevention interventions in addiction treatment (Van Gucht et al., 2008, 2010).

However, there is scarcity of research regarding the involvement of impulsivity traits in the hedonic and expectancy aspects of conditioned responses. This is unfortunate because the results of this line of research could have serious implications for understanding and treating addiction and eating disorders. Assuming that cue reactivity has a learned component, impulsivity traits may influence cue reactivity by being directly involved in the learning processes, e.g., in the acquisition and extinction processes. In this case, people who are more impulsive would acquire and/or extinguish pavlovian responses differently than less impulsive people.

Traditionally, the association between pavlovian conditioning and personality has been viewed within the framework of Eysenck's and Gray's theories (Corr, Pickering, \& Gray, 1995). In Eysenck's arousal theory, it is assumed that there is a single conditionability factor hence there is no discrimination between appetitive and aversive conditioning (Corr et al., 1995). It is assumed that under conditions of moderate arousal, highly aroused people such as introverts would be more easily conditioned than people low in arousal such as extraverts, in both appetitive and aversive conditioning tasks (Zinbarg \& Mohlman, 1998). Unlike Eysenck's arousal theory, in Gray's theory, there are two distinct neuropsychological systems for appetitive and aversive conditions respectively. The Behavioural Activation System (BAS) is activated by reward signals and elicits approach behaviour. Impulsivity is associated with sensitivity of this system (Matthews \& Gilliland, 1999). On the other hand, responses to aversive stimuli are mediated by the Behavioural Inhibition System, which inhibits approach behaviour (Corr et al., 1995). Trait anxiety is associated with sensitivity of the BIS (Matthews \& Gilliland, 1999). Within Gray's theory, introverts are people high in BIS and low in BAS and extraverts are impulsive people who are low in BIS and high in BAS (Corr et al., 1995; Matthews \& Gilliland, 1999). However, the role of BAS/BIS systems in conditioning can be viewed from both a motivational and an associative point of view and different predictions can be derived from each perspective (Zinbarg \& Mohlman, 1998). From a motivational perspective, the BAS/BIS systems are not involved in the acquisition of pavlovian conditioning. In this view, these systems are activated by already established appetitive and aversive conditioned stimuli and their role is merely to moderate the motivational properties of these stimuli (Corr, 2001). On the other hand, an associative interpretation of the theory views cognitive mechanisms essential components of the BAS/BIS systems (Zinbarg \& Mohlman, 1998). Assuming that separate cognitive mechanisms are necessary for the development of appetitive and aversive associations, it can be predicted that the strength and number of aversive and appetitive cognitive resources that constitute these mechanisms are positively associated with BIS and BAS activity, respectively (Zinbarg \& Mohlman, 1998). In other words, it is expected that a higher BAS activity will be associated with a higher speed of acquisition in appetitive associative learning, and a higher BIS activity will be associated with a faster acquisition in aversive associative learning (Zinbarg \& Mohlman, 1998). Consistent with the associative perspective, Gray's theory, like Eysenck's theory, regards introverts as better conditioned than extraverts in aversive conditioning tasks (Corr, 2004; Corr et al., 1995). However, the two theories have different predictions for the conditionability of extraverts/introverts in appetitive conditions. In contrast to Eysenck's theory, Gray's theory predicts that regardless of arousal levels, extraverts would be more sensitive to appetitive conditioning than introverts (Corr, 2004; Corr et al., 1995).

Assuming that Gray's theory is right, the rationale for the effect of impulsivity on the acquisition phase of appetitive pavlovian learning is that following the appearance of the CS+, the presence of the appetitive US (food, and drug) stimulates the impulsivity system (e.g., BAS) and as a result causes arousal and emotional changes that strengthen the CS-US bond in the working memory (Corr, 2001). Alternatively, impulsivity traits could only be involved in the motivational properties of the conditioned stimuli (CS) after pavlovian learning has been established (Corr, 2001; Matthews \& Gilliland, 1999; Zinbarg \& Mohlman, 1998). Finally, most evidence for the involvement of impulsivity traits in cue reactivity comes from studies which assess responding to stimuli that have already been conditioned in the natural environment (Doran et al., 2007, 2008; Papachristou, Nederkoorn, Havermans, et al., 2012; Papachristou et al., 2013; Robbins \& Ehrman, 1992). However, reactivity to naturalistic cues may also consist of unlearned components (Robbins \& Ehrman, 1992). For example, substance users and patients with eating disorders may respond more intensely to any salient/arousing stimuli than control participants and not only to substance- or food-related cues (Robbins \& Ehrman, 1992). In turn, this unlearned arousal could be misinterpreted as craving under the demand effects of their participation in a cue-reactivity study (Robbins \& Ehrman, 1992). It could be that some impulsivity traits are sensitive to these unlearned components of cue reactivity. However, it is important to emphasize that this is only a speculation and that non-specific arousal may not be a key element in all impulsivity systems. For example, unlike Eysenck's model, in Gray's model arousal in general is not a key element of sensitivity to reward (Matthews \& Gilliland, 1999). Despite these limitations, our point is that in order to know if impulsivity indeed moderates pavlovian learning, there is a need to create conditioned stimuli $(\mathrm{CS}+, \mathrm{CS}-$ ) in the laboratory and to test this hypothesis in individuals without extensive histories with the US.

In order to gain a deeper insight into the mechanisms underlying cue reactivity, we used a pavlovian conditioning procedure similar to Van Gucht et al.'s (2010) study. The first aim of the present study was to replicate Van Gucht et al.'s (2010) findings, concerned with the acquisition and especially the differential 
extinction of learned subjective responses (craving, expectancy and liking). In particular, it is expected that relative to the CS-, craving for chocolate in response to the CS+ and liking for the $\mathrm{CS}+$ will remain unaffected after extinction, while expectancy for chocolate in the presence of the CS+ will be extinguished.

The second aim of the present study was to investigate whether impulsivity affects the acquisition and the extinction processes in appetitive learning. However, impulsivity is a multidimensional construct measured with a variety of behavioural and self-report instruments (Dawe \& Loxton, 2004; Dom, De Wilde, Hulstijn, \& Sabbe, 2007; Verdejo-Garcia et al., 2008). It also appears that there is a weak association between self-report and behavioural measures of impulsivity (Dom et al., 2007). For example, Dom et al. (2007) reported that the Sensation Seeking Scale (SSS) is not correlated with the Go/No-Go task, a behavioural measure of response inhibition, in abstinent alcohol-dependent people. The weak association between these two types of impulsivity measurement indicates that each type may assess different aspects of the construct (Dom et al., 2007). In the same vein, Dawe and Loxton (2004) report that in factor analytic studies, self-report measures of sensitivity to reward based on Gray's model load on a different factor from self-report impulsivity measures based on Zuckerman's, Cloninger's, and Eysenck's personality models. As a single measure of impulsivity cannot capture the whole spectrum of impulsive behaviour, we use multiple impulsivity measures in the present study, both behavioural and self-report, in order to explore the role of impulsivity in appetitive learning. We have chosen three impulsivity measures because each of them taps different aspects of the construct: a behavioural measure of response inhibition (stop signal task), a self-report measure of sensitivity to reward (Behavioural Activation System scale), and a short version of the SSS. Furthermore, all three measures have been implicated in substance use and misuse as well as in normal and disordered eating behaviour (Dawe \& Loxton, 2004; Guerrieri, Nederkoorn, \& Jansen, 2008; Jansen, Klaver, Merckelbach, \& Van den Hout, 1989; Verdejo-Garcia et al., 2008). Finally, there is evidence that two of these measures, a weaker response inhibition and a stronger sensitivity to reward, are associated with a higher reactivity to alcohol cues in social heavy and dependent alcohol drinkers (Kambouropoulos \& Staiger, 2001; Papachristou, Nederkoorn, Corstjens, et al., 2012; Papachristou et al., 2013). Since cue reactivity is considered to be a result of pavlovian learning, it is interesting to see if these specific impulsivity measures moderate the intensity of cue reactivity via an effect on pavlovian learning or via different mechanisms.

For each of the three measures of impulsivity in the present study (sensitivity to reward, sensation seeking, and response inhibition), it was hypothesized that in the acquisition phase, more vs. less impulsive people would acquire a faster and stronger craving and expectancy response for chocolate to the CS+ and a stronger liking for the $\mathrm{CS}+$, relative to the $\mathrm{CS}-$. Additionally, during the extinction phase, it was hypothesized that there would be a differential extinction of these acquired subjective responses between more and less impulsive participants. More specifically, it was expected that highly impulsive participants would not extinguish their subjective CRs, while less impulsive participants would extinguish them successfully.

\section{Methods}

\section{Participants}

Fifty (39 women and 11 men) participants with a mean age of 22.58 years, $(S D=4.77)$ volunteered to participate in the study. All participants were recruited via advertisements in the university premises. Only participants who were able and willing to consume milk chocolate in the laboratory were allowed to take part in the study. They were rewarded for their participation in the experiment with either course credits or a gift certificate of $10 €$.

\section{Materials}

Similar to Van Gucht et al.'s (2010) study, two serving trays were used as conditional stimuli in the present experiment. The two trays differed from each other in terms of shape and colour. One tray was brown and rectangular and the other one was white and round. One of them was used as the CS+ and the other one as the CS - with the order of assignment counterbalanced across participants. At baseline, participants liked equally the two trays, $t$ $(49)=-1.081$, ns. The unconditional stimulus (US) was milk chocolate (Bonbiance Napolitains melk). Each piece of chocolate weighed $4 \mathrm{~g}$.

\section{Measures}

Sensitivity to reward (STR): STR was measured with the BAS subscale from the BIS/BAS scale (Carver \& White, 1994; Franken, Muris, \& Rassin, 2005). The BIS/BAS scale is a 24-item self-report instrument, which assesses the sensitivity of the Behavioural Inhibition System (BIS: seven items) and the Behavioural Approach System (BAS: 13 items) (Carver \& White, 1994). Additionally, the BAS scale is subdivided into three subscales: Fun Seeking (four items), Reward Responsiveness (five items), and Drive (four items). In the present study, the Dutch version of the BIS/BAS was used (Franken et al., 2005). The BAS had a good internal consistency, with a Cronbach alpha coefficient of .79.

\section{Response inhibition}

The Stop Signal Task (SST) was used to assess response inhibition or the (in) ability to stop a prepotent response (Logan, Schachar, \& Tannock, 1997). The task consists of two types of trials: go trials and stop trials. Each go trial begins with a fixation cross in the centre of the screen. The fixation cross vanishes after $500 \mathrm{~ms}$ and then a geometrical (square) pattern is displayed either on the left or the right part of the screen. Participants are asked to respond to the pattern as fast as they can by pressing either the left or right "shift" button, respectively. However, in $25 \%$ of the go trials, after the go-signal a $1000 \mathrm{~Hz}$ sound is emitted through headphones (stop signal) signifying to the participants that they have to hold back their response. Initially, the acoustic stop signal is emitted at $250 \mathrm{~ms}$ after the go signal presentation but during the task the stop signal delay varies according to participant's performance. These adjustments allow participants to successfully withhold their responses at approximately $50 \%$ of the stop trials. The dependent variable in the task is the stop signal reaction time (SSRT). A higher SSRT is taken as an index of impaired response inhibition because it indicates that more time is required for an individual to inhibit a prepotent response.

The short Sensation Seeking Scale (sSSS; Madsen, Das, Bogen, \& Grosman, 1987): The scale contains ten forced-choice items. The participant has to choose the one that best suits his/her preference. High sensation-seeking items are scored as 1 and low sensation-seeking items are scored as 0 . The total score ranges from 0 (minimum sensation seeking) to 10 (maximum sensation seeking). This scale has been shown to be a valid and reliable measure of the sensation seeking construct (Jansen et al., 1989; Madsen et al., 1987).

Craving, US-expectancy and liking were measured with the same $10-\mathrm{cm}$ visual analogue scales (VASs) used in Van Gucht et al.'s (2010) study. Regarding craving, participants were asked: "When presented with this tray, how strong is your craving for chocolate 
right now?". The VAS for craving ranged from "no craving at all" to "extremely strong craving". As regards US-expectation, the VAS scale was accompanied by the following question: "How strongly do you now expect to be invited to eat chocolate?" ranging from "certainly not" to "certainly". Finally, concerning liking, participants were asked: "To what extent do you find the white (brown) tray pleasant/unpleasant?" ranging from "very unpleasant" to "very pleasant".

\section{Procedure}

The experiment consisted of one laboratory session lasting approximately $1 \mathrm{~h}$ and arranged between $12.30 \mathrm{pm}$ and $19.00 \mathrm{pm}$. Ethical approval was obtained from the Ethical Committee of the Psychology Faculty of Maastricht University. Initially, participants had to read and sign the informed consent form and then fill out a brief demographic questionnaire. Following this, they were presented with the two personality questionnaires (the BAS/BIS and the SSS) and the SST in a counterbalanced order. Then, the craving and US-expectancy VASs were shown to them and the meaning of these concepts was clarified by the experimenter. After that, participants were given instructions similar to those in Van Gucht et al.'s (2010) (cited in p. 690) study: “Here you see two different serving trays. I will present you with those trays in a randomized order, determined beforehand on the basis of coin tosses. One tray will sometimes be followed by me asking you to eat something, the other tray not". Finally, just before the acquisition phase (baseline), participants were presented with the two trays and asked to rate their liking for each tray.

Then, the acquisition phase started. It consisted of eight trials, four (A1-A4) for the CS+ and the CS-, respectively. The two trays were presented in a random order as described in the instructions with the constraint that no more than two consecutive trials were the same. In each trial, the experimenter put the tray on participant's view for $10 \mathrm{~s}$ and asked them to concentrate on it and on their feelings and thoughts at the time of presentation (Van Gucht et al., 2010). Then, participants were required to rate their craving and expectancy for chocolate on the VASs. The VASs for craving and expectancy were administered in counterbalanced order across participants. In a CS+ trial, participants were always offered a piece of chocolate and were instructed to eat it. Following this, the tray was always placed in a shopping bag out of participant's view. In a CS - trial, no chocolate was offered and the tray was placed in the shopping bag immediately after the VASs completion. The

Table 1

Mean, minimum, and maximum scores and standard errors on the SST, BAS, and sSSS.

\begin{tabular}{lrlll}
\hline Measures of impulsivity & Mean & SE & Minimum & Maximum \\
\hline $\begin{array}{l}\text { Stop Signal Task (SSRT) } \\
\begin{array}{l}\text { Behavioural Activation System } \\
\quad \text { (BAS) scale }\end{array}\end{array}$ & 236.81 & 5.36 & 158.16 & 314.14 \\
$\begin{array}{l}\text { Short Sensation Seeking Scale (sSSS) } \\
\text { She.32 }\end{array}$ & 0.66 & 28 & 50 \\
\hline
\end{tabular}

Note: $n=50$.

Table 2

Mean scores, standard errors, number of participants, $t$-tests, degrees of freedom, and $P$ values for high and low scores (median split) in each impulsivity measure.

\begin{tabular}{|c|c|c|c|c|c|c|c|}
\hline & \multicolumn{2}{|l|}{ Mean } & \multicolumn{2}{|l|}{ SE } & \multirow[t]{2}{*}{ t-test } & \multirow[t]{2}{*}{ df } & \multirow[t]{2}{*}{$P$ value } \\
\hline & High in impulsivity & Low in impulsivity & High in impulsivity & Low in Impulsivity & & & \\
\hline SSRT & $\begin{array}{l}267.25 \\
N=25\end{array}$ & $\begin{array}{l}206.36 \\
N=25\end{array}$ & 24.13 & 20.35 & -9.65 & 48 & $P<.001$ \\
\hline BAS & $\begin{array}{l}44.17 \\
N=24\end{array}$ & $\begin{array}{l}36.77 \\
N=26\end{array}$ & 0.48 & 0.63 & -9.24 & 48 & $P<.001$ \\
\hline sSSS & $\begin{array}{l}7.67 \\
N=21\end{array}$ & $\begin{array}{l}4.34 \\
N=29\end{array}$ & 0.14 & 0.28 & -10.5 & 40.59 & $P<.001$ \\
\hline
\end{tabular}

intertrial interval was $10 \mathrm{~s}$. At the end of the acquisition phase, participants were required to fill out the liking VAS.

The extinction phase followed the acquisition phase. It consisted of 16 trials, eight (E1-E8) for the CS+ and the CS-, respectively, presented in a random order as in the acquisition phase. Extinction trials were identical to the acquisition trials except for the fact that no chocolate (and chocolate eating) was paired with the CS+. At the end of the extinction phase, participants were once more instructed to rate their liking for each tray on a VAS. After the extinction phase, participants were debriefed, thanked, and rewarded for their participation in the experiment.

\section{Statistical analysis}

The SSRTs, sSSS and BAS scores were centred and entered as covariates in the analysis. There was no significant correlation between the three impulsivity measures. Inspection of the histograms, box-plots, and tests of normality showed that there were no outliers and that each of three impulsivity measures was normally distributed. In order to confirm the differential acquisition of the learned responses between CS+ and CS-, a two-way 2 (Cue type: $\mathrm{CS}+$ vs. $\mathrm{CS}-$ ) by 4 (Trial: Trial A1 vs. Trial A2 vs. Trial A3 vs. Trial A4) repeated-measures ANCOVA was performed on craving and expectancy ratings, respectively. Regarding liking, a similar two-way 2 (Cue type: $\mathrm{CS}+$ vs. $\mathrm{CS}_{-}$) by 2 (Phase: baseline vs. end of acquisition phase) repeated measures ANCOVA was performed. In addition, interactions with the covariates were also tested. When further analysis was required, a median split was conducted on an impulsivity measure in order to classify participants as being either high or low on this trait. Finally, to demonstrate the generalization of learning from the acquisition to the extinction phase, a 2 (Cue type: CS+ vs. CS-) by 2 (Trial: A4 vs. E1) repeated measures ANCOVA was conducted on expectancy and craving responses.

To investigate the differential extinction of the learned responses between CS+ and CS-, a 2 (Cue-type: CS+ vs. CS-) by 8 (Trial: E1 vs. E2 vs. E3 vs. E4 vs. E5 vs. E6 vs. E7 vs. E8) repeated measures ANCOVA was performed on expectancy and craving ratings, respectively. A similar 2 (Cue type: CS+ vs. CS-) by 2 (Phase: end of acquisition vs. end of extinction) repeated measures ANCOVA was performed on liking. Interactions with the covariates were also tested. When further analysis was required, a median split was performed on an impulsivity measure (see Table 1 and 2).

\section{Results}

\section{Self-reported expectancy rating}

\section{Acquisition}

The two-way interaction CS type (CS+ vs. CS-) by Trial (A1 vs. A2 vs. A3 vs. A4) on expectancy rating was significant, $F$ $(2.61,119.86)=12.3, p<.001$ (Fig. 1). Regarding the CS+, there was a statistically significant increase in expectancy during the acquisition phase, $F(1,46)=35.05, p<.001$. With regard to the 
Changes in expectancy during the acquisition and extinction phases

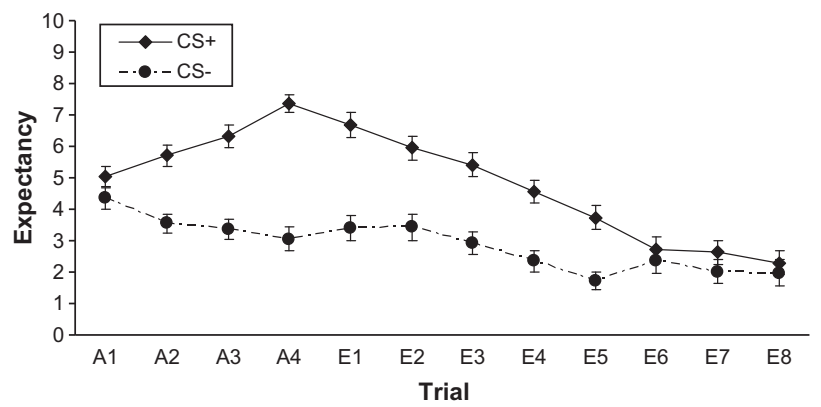

Fig. 1. Mean expectancy (for chocolate) scores and S.E.M. in response to the CS+ and $\mathrm{CS}-$ across the acquisition and the extinction phases.

CS -, there was a statistically significant decrease in expectancy during this phase, $F(1,46)=7.7, p=.008$. At the end of the acquisition phase (Trial A4), CS+ elicited significantly higher expectancy for chocolate than CS $-, F(1,46)=70.97, p<.001$. Impulsivity traits did not affect the acquisition of the strength of the expectancy response. None of the three-way interactions on expectancy rating was statistically significant (BAS: $F(2.61,119.86)=0.48$, ns; SSS: $F(2.61,119.86)=0.67$, ns; SSRT: $F(2.61,119.86)=0.79$, ns $)$.

\section{Transition from acquisition to extinction}

The two-way interaction CS type (CS+ vs. CS-) by Trial (A4 vs. E1) on expectancy was not significant, $F(1,46)=2.05$, ns. The main effect of Trial was also not significant, $F(1,46)=0.55$, ns. The main effect of CS type was significant, $F(1,46)=64.1, p<.001$. In general, the CS+ elicited more expectancy for chocolate than the CS-. The results show that the acquired expectancy response was maintained from the end of the acquisition phase to the beginning of the extinction phase (Fig. 1).

\section{Extinction}

The extinction of the expectancy response was successful. The two-way interaction CS type (CS+ vs. CS-) by Trial (E1 vs. E2 vs. E3 vs. E4 vs. E5 vs. E6 vs. E7 vs. E8) on expectancy was highly significant, $F(4.16,191.36)=10.26, p<.001$ (Fig. 1). At the end of extinction (Trial E8), there was no significant difference in expectancy ratings between $\mathrm{CS}+$ and $\mathrm{CS}-, F(1,46)=0.74$, ns. Impulsivity traits did not play a role in the extinction of the expectancy response. None of the three-way interactions on expectancy rating was statistically significant (BAS: $F(4.16,191.36)=0.59$, ns; SSS: $F(4.16,191.36)=0.48$, ns; SSRT: $F(4.16,191.36)=2.03$, ns $)$. However, there was a significant two-way interaction CS type by BAS on expectancy, $F(1,46)=4.86, p=.032$. Further analysis showed that there was no difference in the expectancy response to the CS+ between high and low sensitive to reward participants, $F$ $(1,46)=0.73$, ns. However, there was a marginally significant difference in the expectancy response to the CS - between high and low sensitive to reward participants, $F(1,46)=3.83, p=.056$. High BAS participants responded more strongly to the CS - than low BAS participants.

\section{Self-reported craving rating}

\section{Acquisition}

There was a significant two-way interaction CS type (CS+ vs. CS-) by Trial (A1 vs. A2 vs. A3 vs. A4) on craving for chocolate, $F$ $(2.17,99.92)=6.28, p=.002$ (Fig. 2). Further analysis indicated that craving in response to the CS+ increased significantly during the acquisition phase, A1 vs. A4: $F(1,46)=6.79, p=.012$. In contrast,
Changes in craving during the acquisition and extinction phases

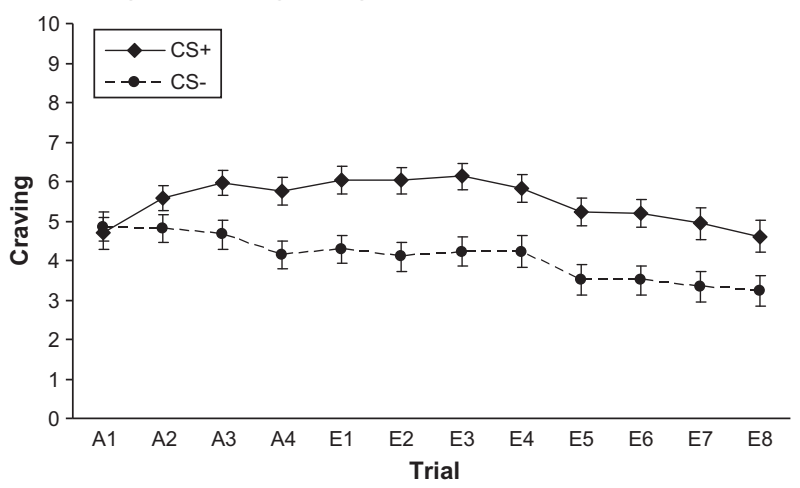

Fig. 2. Mean craving (for chocolate) scores and S.E.M. in response to the CS+ and CS - across the acquisition and the extinction phases.

CS - did not change significantly during this phase, A1 vs. A4: $F$ $(1,46)=3.47, p=.069$. At the end of the acquisition phase (Trial A4), CS+ elicited higher craving than CS-, $F(1,46)=16.65$, $p<.001$. Furthermore, impulsivity traits did not affect the acquisition of craving. None of the three-way interactions on craving rating was statistically significant $($ BAS: $F(2.17,99.92)=0.21$, ns; SSS: $F(2.17,99.92)=1.02$, ns; SSRT: $F(2.17,99.92)=0.08$, ns $)$.

\section{Transition from acquisition to extinction}

The analysis showed that the two-way interaction CS type (CS+ vs. CS-) by Trial (A4 vs. E1) on craving was not significant, $F$ $(1,46)=.35$, ns. Additionally, there was a non-significant main effect of Trial (A4 vs. E1) on craving, $F(1,46)=1.05$, ns. Finally, there was a significant main effect of CS type (CS+ vs. CS-) on craving, $F$ $(1,46)=22.69, p<.001$. Overall, the CS+ elicited higher craving than the CS-. These findings illustrate that the learned craving response did generalize to the first extinction trial (E1) (Fig. 2).

\section{Extinction}

The extinction of the learned craving response was not successful. The two-way interaction CS type (CS+ vs. CS-) by Trial (E1 vs. E2 vs. E3 vs. E4 vs. E5 vs. E6 vs. E7 vs. E8) on craving was not significant showing that the extinction phase did not reduce the acquired differentiation in craving between the CS+ and the CS-, $F$ $(2.83,130.37)=0.54$, ns (Fig. 2). At the end of extinction (Trial E8), there was a significant difference in craving ratings between the CS+ and the CS $-, F(1,46)=23.11, p<.001$. Impulsivity traits did not play a role in the extinction of the craving response. None of the three-way interactions on craving was statistically significant $($ BAS: $F(2.83,130.37)=0.59$, ns; SSS: $F(2.83,130.37)=1.26$, ns; SSRT: $F(2.83,130.37)=0.5$, ns). Nevertheless, there was a main effect of BAS on craving during this phase, $F(1,46)=6.1, p=.017$. In general, during extinction, participants with higher BAS scores experience higher overall craving $(M=5.23, \mathrm{SE}=0.44)$ than participants with lower BAS scores $(M=3.90, \mathrm{SE}=0.42)$.

\section{Self-reported liking rating}

\section{Acquisition}

There was a significant two-way interaction CS type (CS+ vs. CS - ) $\times$ Phase (Baseline vs. end of acquisition phase) on liking, $F$ $(1,46)=36.43, p<.001$ (Fig. 3). Further analysis indicated that there was a slight but significant increase in liking rating for the CS+ from baseline to the end of acquisition, $F(1,46)=6.04$, $p=.018$. In addition, there was a significant decrease in liking rating for the $\mathrm{CS}$ - from baseline to the end of acquisition phase, $F$ 


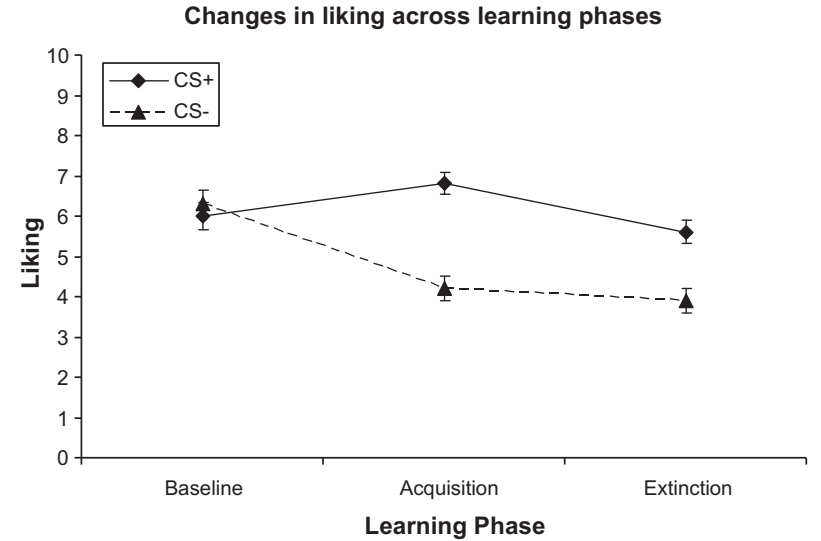

Fig. 3. Mean liking scores and S.E.M. for the CS+ and CS- across the acquisition and the extinction phases.

$(1,46)=51.35, p<.001$. At the end of the acquisition phase, participants liked the CS+ significantly more than the CS-, $F$ $(1,46)=28.44, p<.001$. Finally, there was no significant effect of any impulsivity measure on the acquisition of the liking response (Sensation Seeking: $F(1,46)=0.17$, ns; BAS: $F(1,46)=1.09$, ns; SSRT: $F(1,46)=0.00$, ns. $)$.

\section{Extinction}

Extinction of the liking response was not fully successful in the present experiment. Although the two-way interaction CS type (CS+ vs. CS - ) by Phase (end of acquisition vs. end of extinction) on liking was significant, $F(1,46)=5.83, p=.020$, participants still liked more the CS+ than the CS - at the end of the extinction phase, $F(1,46)=13.7, p<.001$, (Fig. 3 ). The liking rating for the CS+ significantly decreased during extinction, $F(1,46)=16.37, p<.001$. On the other hand, there was no statistically significant decrease in the liking rating for the $\mathrm{CS}$ - during this phase, $F(1,46)=2.35$, ns. Finally, there was a significant two-way interaction BAS by Phase on liking rating, $F(1,46)=4.26, p=.045$. Additional analysis demonstrated that both high and low BAS scorers experience a decrease in liking, regardless of CS type (High BAS: $F(1,21)=12.15$, $p=.002$; Low BAS: $F(1,23)=5.22, p=.028$ ). However, it appears that the decrease in liking is larger in high BAS scorers (end of acquisition phase: $M=5.43, \mathrm{SE}=0.22$; End of extinction phase: $M=4.31$, $\mathrm{SE}=0.33$ ) than in low BAS scorers (End of acquisition phase: $M=5.58, \mathrm{SE}=0.21$; End of extinction phase: $M=5.16, \mathrm{SE}=0.22$ ).

\section{Discussion}

The purpose of the present study was (i) to replicate Van Gucht et al.'s (2010) findings, concerned with the acquisition and the differential extinction of appetitive learned subjective responses (craving, expectancy and liking) and (ii) to investigate the role of impulsivity traits in appetitive learning. Our findings give support to the first aim of the present study but we find no supportive evidence for the role of impulsivity traits in appetitive learning.

First of all, the differential conditioning paradigm used in the present study led to a successful acquisition of the three appetitive conditioned responses. At the end of the acquisition phase, participants showed increased craving and expectancy for chocolate in response to the CS+ and more liking for the $\mathrm{CS}+$, relative to the CS-. These findings are similar to Van Gucht et al.'s (2010) and Van Gucht et al.'s (2008) findings and support the validity of the conditioning paradigm. Additionally, the present results suggest a role for conditioning in appetitive cue reactivity and are in line with the results of earlier conditioning studies in the field of substance abuse (Field \& Duka, 2001; Lazev, Herzog, \& Brandon,
1999). However, as in previous studies, our findings do not exclude other sources of cue reactivity that may not be related to associative learning (Lazev et al., 1999; Robbins \& Ehrman, 1992).

The present study also supports the differential extinction of the subjective appetitive responses. Unlike expectancy for chocolate, the acquired difference in craving was not extinguished successfully and the acquired difference in liking was only partially extinguished. At the end of the extinction phase, participants still liked the CS+ more than the $\mathrm{CS}$ - and craved chocolate more in response to the CS+ relative to the CS-. In general, our results provide support to Van Gucht et al.'s (2010) findings and illustrate a desynchrony of these appetitive conditioned responses during extinction but not during acquisition. This desynchrony does not imply that cue-elicited craving cannot be extinguished successfully in therapy or after including more extinction trials or sessions in the procedure. Evidence from both clinical and laboratory studies suggest that cue-elicited craving can be successfully extinguished under certain conditions (Boutelle et al., 2011; Conklin \& Tiffany, 2002; Jansen, 1998; Van Gucht et al., 2008). The present findings highlight a differential sensitivity of these appetitive responses to extinction, resulting perhaps from the different nature of these response systems. The difficulty in the extinction of cue-elicited craving resembles the difficulty in extinguishing evaluative conditioned responses that is often reported in the literature, though in the present study the acquired difference in liking was partially extinguished (De Houwer, Thomas, \& Baeyens, 2001; Van Gucht et al., 2010). On the other hand, conditioned expectancies for reward may reflect a system that prepares an individual to process a salient stimulus independent of its evaluative value (Van Gucht et al., 2008). Yet, this differential sensitivity may have important clinical implications showing that even after successful extinction of reward expectancies, cue-elicited craving and liking for the conditioned stimulus could still remain perhaps posing a potential threat for relapse (Van Gucht et al., 2008, 2010).

In the present study, we find no supportive evidence for the role of impulsivity traits in the acquisition and extinction processes of appetitive conditioning. Our results are in agreement with the findings of another study conducted in our laboratory, which showed that trait impulsiveness is not related with the acquisition of a learned craving response for an appetitive food (milkshake) but only with overeating (Van den Akker, Jansen, Frentz, \& Havermans, submitted for publication). It is possible that other learning mechanisms are influenced by impulsivity. Perhaps impulsive people show stronger habit learning, meaning that the CS+ has more influence on behaviour, albeit not on craving. However, the role of stimulus strength may be of importance in the present study (Matthews \& Gilliland, 1999). For example, in an early conditioning study by Paisey and Mangan (1988), it was found that extraversion was negatively related to the acquisition of the electrodermal CR to weak sexual stimuli and positively related to the acquisition of the same CR to strong sexual stimuli. In the present study, the appetitive US was milk chocolate that might have been a weak arousing stimulus for the participants. It could be that a more novel or arousing US (e.g., a novel food, a substance of abuse, or even a personally relevant US such as participants' favourite brand of chocolate) may have resulted in a different outcome. This is an empirical question, however, that can be answered with further research.

Alternatively, impulsivity may be involved in the expression of the motivational properties of the conditioned stimuli (CS) after pavlovian learning has been established (Corr, 2001; Matthews \& Gilliland, 1999; Pickering \& Gray, 1999; Zinbarg \& Mohlman, 1998). This assumption fits well with the findings of cue reactivity studies in the field of substance abuse where the substance-related cues are considered to be well-established conditioned stimuli as a result of their association with the effects of the substance prior to 
the experiment (Doran et al., 2007, 2008; Franken, 2002; Kambouropoulos \& Staiger, 2001; Papachristou, Nederkoorn, Havermans, et al., 2012; Papachristou et al., 2013). A more thorough way to test empirically this assumption would be to examine the effects of impulsivity traits on the ability of a well-established CS+ to motivate behaviour in conditioned reinforcement and pavlovian-toinstrumental paradigms (Bouton, 2007; Corr, 2001).

Finally, the effect of impulsivity on cue-reactivity may be related to unlearned components of cue reactivity. According to Robbins and Ehrman (1992), substance users may feel aroused when faced with substance-related cues because they simply find them to be disturbing. Alternatively, substance users or patients with eating disorders may in general react more strongly to any salient and arousing stimuli than control participants, independent of their conditioning history (Robbins \& Ehrman, 1992). In turn, this general arousal could be misinterpreted as craving under the demand effects of their participation in a cue-reactivity study (Robbins \& Ehrman, 1992). It could be that the increased cue-elicited craving in impulsive participants (Doran et al., 2007, 2008; Franken, 2002; Kambouropoulos \& Staiger, 2001; Papachristou, Nederkoorn, Havermans, et al., 2012; Papachristou et al., 2013) reflects sensitivity of some impulsivity measures to these unlearned components of cue reactivity. This means that the impulsive participants might not form stronger associations between the CS+ and the US but are more easily aroused by salient cues hence, their response is more intense. For heavy and dependent substance users, however, the presence of their substance of choice in the lab could be particularly arousing, while chocolate could be a less salient and therefore arousing stimulus for the participants of the present study.

Our analysis indicated that independent of cue type or trial, participants who were more sensitive to reward (BAS) experience stronger craving for chocolate during the extinction phase. Additionally, their liking response in general was reduced faster than the liking response of participants who were less sensitive to reward. Obviously, reward sensitive participants did not respond to the specific CS+ of the experiment but to something else. Speculating on the nature of these responses, one explanation could be that simply being informed about the nature of the experiment and expecting chocolate in the lab acted as a CS+ that activated the BAS system (Corr, 2001). The contrast between these expectations and the fact of not receiving chocolate any more during the extinction phase may have caused greater disappointment to more vs. less sensitive to reward participants, which resulted in a faster decline in their liking response and more craving.

There are several limitations in our study. For example, the cue reactivity components in the present study are subjective hence vulnerable to demand characteristics. On the other hand, our study was a replication of Van Gucht et al.'s (2010) study and the fact that we and Van Gucht et al. (2010) report similar results gives support to the findings of both studies. However, even if we assume that demand characteristics played a role in both studies, we would still have to explain why different appetitive conditioned responses showed a clearly different extinction pattern in both studies. Nevertheless, we believe that future research should address these questions by including both subjective and psychophysiological cue reactivity measures in the experimental design in order to minimize the influence of demand characteristics on participants' behaviour. Finally, we did not control for the effects of individual differences such as participants' BMI and of motivational states such as hunger on appetitive conditioning. For example, different BMIs could mean different histories with the US (chocolate) and as a result different cue reactivity to chocolate.

Despite the limitations, the findings of the present study offer deeper insight to the mechanisms involved in appetitive conditioning. The dissection of the appetitive response systems and their differential sensitivity to extinction appears to be a relatively robust finding that may stimulate further research in the field of appetitive learning and may enable us to understand some of the theoretical and clinical problems in the field of substance and eating disorders. Additionally, the findings that impulsivity traits are not involved in appetitive learning mechanisms are important. More research is needed to sort out how impulsivity traits influence consumptive behaviour: via different learning mechanisms or via routes unrelated to learning. Deeper understanding of the topic might prove useful for the development of more effective treatment of substance and eating disorders.

\section{References}

Birch, L. L., McPhee, L., Sulivan, S., \& Johnson, S. (1989). Conditioned meal initiation in young children. Appetite, 13, 105-113.

Boutelle, K. N., Zucker, N. L., Peterson, C. B., Rydell, S. A., Cafri, G., \& Harnack, L. (2011). Two novel treatments to reduce overeating in overweight children. A randomized controlled trial. Journal of consulting and clinical psychology, 79(6), 759-771.

Bouton, M. E. (2007). Learning and behavior. A contemporary synthesis. Sunderland, Massachusetts: Sinauer Associates, Inc.

Carter, B. L., \& Tiffany, S. T. (1999). Meta-analysis of cue-reactivity in addiction research. Addiction, 94(3), 327-340.

Carver, C. S., \& White, T. L. (1994). Behavioral inhibition, behavioral activation, and affective responses to impending reward and punishment. The BIS/BAS scales. Journal of Personality and Social Psychology, 67, 319-333.

Conklin, C. A., \& Tiffany, S. T. (2002). Applying extinction research and theory to cueexposure addiction treatments. Addiction, 97, 155-167.

Cornell, C. E., Rodin, J., \& Weingarten, H. (1989). Stimulus-induced eating when satiated. Physiology and Behavior, 45, 695-704.

Corr, P. J. (2001). Testing problems in J.A. Gray's personality theory. A commentary on Matthews and Gilliland (1999). Personality and Individual Differences, 30, $333-352$.

Corr, P. J. (2004). Reinforcement sensitivity theory and personality. Neuroscience and Biobehavioral Reviews, 28, 317-332.

Corr, P. J., Pickering, A. D., \& Gray, J. A. (1995). Personality and reinforcement in associative and instrumental learning. Personality and Individual Differences, 19, 47-71.

Dawe, S., \& Loxton, N. J. (2004). The role of impulsivity in the development of substance use and eating disorders. Neuroscience and Biobehavioral Reviews, 28 , 343-351.

De Houwer, J., Thomas, S., \& Baeyens, F. (2001). Associative learning of likes and dislikes. A review of 25 years of research on human evaluative conditioning. Psychological Bulletin, 127, 853-869.

Dom, G., De Wilde, B., Hulstijn, W., \& Sabbe, B. (2007). Dimensions of impulsive behaviour in abstinent alcoholics. Personality and Individual Differences, 42, $465-476$.

Doran, N., McChargue, D., \& Spring, B. (2008). Effect of impulsivity on cardiovascular and subjective reactivity to smoking cues. Addictive Behaviors, 33, 167-172.

Doran, N., Spring, B., \& McChargue, D. (2007). Effects of impulsivity on craving and behavioural reactivity to smoking cues. Psychopharmacology, 194, 279-288.

Drummond, D. C. (2001). Conceptualizing addiction. Theories of drug craving, ancient and modern. Addiction, 96, 33-46.

Ferriday, D., \& Brunstrom, J. M. (2011). "I just can’t help myself”. Effects of food-cue exposure in overweight and lean individuals. International Journal of Obesity, 35 , $142-149$

Field, M., \& Duka, T. (2001). Smoking expectancy mediates the conditioned responses to arbitrary smoking cues. Behavioural Pharmacology, 12 183-194.

Franken, I. H. A. (2002). Behavioural approach system (BAS) predicts alcoho craving. Personality and Individual Differences, 32, 349-355.

Franken, I. H. A., Muris, P., \& Rassin, E. (2005). Psychometric properties of the Dutch BIS/BAS scales. Journal of Psychopathology and Behavioral Assessment, 27, 25-30.

Guerrieri, R., Nederkoorn, C., \& Jansen, A. (2008). The effect of an impulsive personality on overeating and obesity. Current state of affairs. Psychological Topics, 17, 265-286.

Jansen, A. (1998). A learning model of binge eating. Cue reactivity and cue exposure Behaviour Research and Therapy, 36, 257-272.

Jansen, A., Klaver, J., Merckelbach, H., \& Van den Hout, M. (1989). Restrained eaters are rapidly habituating sensation seekers. Behaviour Research and Therapy, 27, 247-252.

Kambouropoulos, N., \& Staiger, P. K. (2001). The influence of sensitivity to reward on reactivity to alcohol-related cues. Addiction, 96, 1175-1185.

Lazev, A. B., Herzog, T. A., \& Brandon, T. H. (1999). Classical conditioning of environmental cues to cigarette smoking. Experimental and Clinical Psychopharmacology, 7, 56-63.

Logan, G. D., Schachar, R. J., \& Tannock, R. (1997). Impulsivity and inhibitory control. Psychological Science, 8(1), 60-64.

Madsen, D. B., Das, A. K., Bogen, I., \& Grosman, E. E. (1987). A short sensation seeking scale. Psychological Reports, 60, 1179-1184. 
Matthews, G., \& Gilliland, K. (1999). The personality theories of H.J. Eysenck and J.A. Gray. A comparative review. Personality and Individual Differences, 26, 583-626.

Paisey, T. J. H., \& Mangan, G. L. (1988). Personality and conditioning with appetitive and aversive stimuli. Personality and Individual Differences, 9 69-78.

Papachristou, H., Nederkoorn, C., Corstjens, J., \& Jansen, A. (2012). The role of impulsivity and perceived availability on cue-elicited craving for alcohol in social drinkers. Psychopharmacology, 224, 145-153.

Papachristou, H., Nederkoorn, C., Havermans, R., Bongers, P., Beunen, S., \& Jansen, A (2013). Higher levels of trait impulsiveness and a less effective response inhibition are linked to more intense cue-elicited craving for alcohol in alcoholdependent patients. Psychopharmacology. http://dx.doi.org/10.1007/s00213013-3063-3.

Papachristou, H., Nederkoorn, C., Havermans, R., van der Horst, M., \& Jansen, A (2012). Can't stop the craving. The effect of impulsivity on cue-elicited craving for alcohol in heavy and light social drinkers. Psychopharmacology, 219, 511-518.

Pickering, A. D., \& Gray, J. A. (1999). The neuroscience of personality. In L. A. Pervin \& O. P. John (Eds.), Handbook of personality. Theory and research (pp. 277-299). New York: Guilford Press.

Robbins, S. J., \& Ehrman, R. N. (1992). Designing studies of drug conditioning in humans. Psychopharmacology, 106, 143-153.
Tetley, A., Brunstrom, J., \& Griffiths, P. (2009). Individual differences in food-cue reactivity. The role of BMI and everyday portion-size selections. Appetite, 52, 614-620.

Toro, J., Cervera, M., Feliu, M. H., Garriga, N., Jou, M., \& Martinez, E. (2003). Cue exposure in the treatment of resistant bulimia nervosa. International Journal of Eating Disorders, 34, 227-234.

Van den Akker, K., Jansen, A., Frentz, F., \& Havermans, R. (submitted for publication). Impulsivity makes more susceptible to overeating after contextual appetitive conditioning.

Van Gucht, D., Baeyens, F., Vansteenwegen, D., Hermans, D., \& Beckers, T. (2010). Counterconditioning reduces cue-induced craving and actual cue-elicited consumption. Emotion, 10, 688-695.

Van Gucht, D., Vansteenwegen, D., Beckers, T., \& Van den Bergh, O. (2008). Return of experimentally induced chocolate craving after extinction in a different context. Divergence between craving for and expecting to eat chocolate. Behaviour Research and Therapy, 46, 375-391.

Verdejo-Garcia, A., Lawrence, A. J., \& Clark, L. (2008). Impulsivity as a vulnerability marker for substance-use disorders. Review of findings from high-risk research, problem gamblers and genetic association studies. Neuroscience and Behavioral Reviews, 32, 777-810.

Zinbarg, R. R., \& Mohlman, J. (1998). Individual differences in acquisition of affectively valenced associations. Journal of Personality and Social Psychology, 74, 1024-1040. 